\title{
METODOLOGIAS ATIVAS DE APRENDIZAGEM NO ENSINO SUPERIOR DE SAÚDE: O FAZER PEDAGÓGICO
}

\author{
METODOLOGÍAS ACTIVAS DE APRENDIZAJE EN LA ENSEÑANZA SUPERIOR DE \\ SALUD: EL HACER PEDAGÓGICO
}

\author{
ACTIVE LEARNING METHODOLOGIES IN HIGHER EDUCATION IN HEALTH: \\ THE PEDAGOGIC DOING
}

\author{
Mariana Dond VELOSO ${ }^{1}$ \\ Alice Maria Correia PEQUENO ${ }^{2}$ \\ Francisca Diana da Silva NEGREIROS ${ }^{3}$
}

RESUMO: Objetivou-se descrever, sob a ótica de docentes do ensino superior, entendimentos acerca das novas metodologias para o fazer pedagógico após um curso de capacitação. Pesquisa quantitativa, realizada com 13 docentes de uma Instituição de Ensino Superior de Fortaleza, Ceará, Brasil. Coleta dos dados de novembro de 2014 a fevereiro de 2015, por meio da oficina de capacitação e observação. Os dados obtidos foram compilados em três aspectos avaliativos: desenvolvimento das competências sobre as metodologias ativas; atividades complementares; método de ensino-aprendizagem quanto à performance nos trabalhos em grupo e o papel do facilitador. Para melhorar o conhecimento sobre metodologias ativas dos docentes, sugerem-se investimentos em cursos de capacitação e treinamento de habilidades sobre estratégias de ensino que facilitarão a superação de abordagem tradicional entre os docentes das instituições de ensino.

PALAVRAS-CHAVE: Ensino. Aprendizagem. Educação superior. Docentes.

RESUMEN: El objetivo fue describir, bajo la óptica de docentes de la enseñanza superior, entendimientos acerca de las nuevas metodologías para el hacer pedagógico, después de un curso de capacitación. Investigación cuantitativa, con 13 docentes de una Institución de Enseñanza Superior de Fortaleza, Ceará, Brasil. Recolección de los datos de noviembre de 2014 a febrero de 2015, a través del taller de capacitación y observación. Datos obtenidos compilados en tres aspectos evaluativos: desarrollo de las competencias sobre metodologías activas; actividades complementares; método de enseñanza-aprendizaje en cuanto a la performance en trabajos en grupo y papel del facilitador. Para mejorar el conocimiento sobre metodologías activas de los docentes, se sugieren inversiones en cursos de capacitación y

${ }^{1}$ Faculdade Nordeste (FANOR), Fortaleza - CE - Brasil. Docente do Curso de Fisioterapia. ORCID: <http://orcid.org/0000-0002-4775-7209>.E-mail: mariana_dond@ hotmail.com

${ }^{2}$ Universidade Estadual do Ceará (UECE), Fortaleza - CE - Brasil. Doutora em Saúde Pública. Docente do Curso de Mestrado Profissional Ensino na Saúde (CMEPES). ORCID: <http://orcid.org/0000-0002-4248-1610>. E-mail: alicepequeno@gmail.com

${ }^{3}$ Universidade Federal do Ceará (UFC), Fortaleza - CE - Brasil. Doutoranda em Saúde Pública. Hospital Universitário Walter Cantídio (HUWC). ORCID: <http://orcid.org/0000-0003-3150-2540>. E-mail: negreiros.diana@gmail.com

RIAEE - Revista Ibero-Americana de Estudos em Educação, Araraquara, v. 14, n. 2, p. 354-370, abr./jun., 2019. E-ISSN: 1982-5587. 
entrenamiento de habilidades sobre estrategias de enseñanza que facilitarán la superación del enfoque tradicional entre docentes de las instituciones de enseñanza.

PALABRAS CLAVE: Enseñanza. Aprendizaje. Educación superior. Docentes.

ABSTRACT: This study aimed to describe, from the perspective of higher education professors, understandings about the new methodologies for pedagogic doing after a training course. It was a quantitative research conducted with 13 professors from a Higher Education Institution of Fortaleza, Ceará, Brazil. Data collection took place from November 2014 to February 2015, through the training and observation workshop. Data obtained were organized in three evaluative aspects: development of competences on active methodologies; complementary activities; teaching and learning method regarding performance in group work and the role of the facilitator. To improve knowledge about active methodologies of professors, it is recommended to invest in training courses and skills training on teaching strategies that will enable to overcome the traditional approach among professors of educational institutions.

KEYWORDS: Teaching. Learning. Higher education. Faculty.

\section{Introdução}

Atualmente, um dos grandes desafios para o profissional que exerce a docência em Instituições de Ensino Superior (IES) é utilizar na prática as Metodologias Ativas (MA) de aprendizagem, as quais constituem diferentes formas de desenvolver o processo do aprender que os professores utilizam com o desígnio da formação crítica de futuros profissionais em várias áreas do saber. Pretende-se, com a aplicação destas favorecer a autonomia do estudante, despertar a curiosidade e estimular tomadas de decisões individuais e coletivas, advindas das atividades essenciais da prática social e nos contextos do estudante (CAMAS; BRITO, 2017).

Portanto, as diretrizes contemporâneas para o ensino da educação superior impetram pedagogias, metodologias e métodos de ensino que viabilizem a formação de profissionais competentes para atender à nova ordem global, cujos potenciais vão além da aquisição de conhecimento cognitivo. Para Mesquita, Meneses e Ramos (2016), a valorização da formação voltada para aquisições de conhecimentos com base na realidade está sendo bastante discutida, o que beneficia a aproximação de teoria e prática e, assim, trabalhar com os problemas reais encontrados nos serviços.

A partir dos enunciados, as IES são consideradas atores principais do processo ensinoaprendizagem do século XXI e precisam compor o corpo docente com capacidade para conhecer e avaliar criticamente o uso de técnicas e estratégias educacionais que viabilizem a

RIAEE - Revista Ibero-Americana de Estudos em Educação, Araraquara, v. 14, n. 2, p. 354-370, abr./jun., 2019. E-ISSN: 1982-5587. 
aprendizagem de forma ativa, formação ancorada no aprendizado reflexivo e crítico, e garantia da qualidade do processo pedagógico.

Nesse sentido, questiona-se: os docentes da IES compreendem o processo de ensino e aprendizado na ação pedagógica que motive o uso de metodologias ativas na prática? Para responder a esse questionamento, traçou-se como objetivo: descrever, sob a ótica de docentes do ensino superior, os entendimentos acerca das novas metodologias para o fazer pedagógico após um curso de capacitação.

Os benefícios deste estudo estão relacionados à possível melhoria do processo ensinoaprendizagem em saúde e todos os demais benefícios que se desdobrarão a curto, médio e longo prazo, como preparação docente mais adequada com as novas propostas metodológicas, possível redução dos índices de evasão discente, mudança dos conceitos da instituição e dos cursos ofertados, probabilidade de aumento da credibilidade educacional e mercadológica da instituição e elevação da qualificação profissional dos discentes em formação.

\section{Metodologia}

Trata-se de pesquisa descritiva, com abordagem quantitativa, realizada em uma Instituição de Ensino Superior (IES) da cidade de Fortaleza, Ceará, Brasil. Esta IES é da rede particular composta por cincos cursos de bacharelado e cinco tecnológicos. Desses, seis tem relação com a atenção à saúde, destacando a Psicologia, Enfermagem, Biomedicina, Fonoaudiologia, Fisioterapia e Radiologia.

Dentre os profissionais do corpo docente, 39 ministravam aulas nos cursos de bacharelado na área da saúde. A amostragem foi intencional e, com base nos critérios, foram convidados 22 docentes, destes, 13 aceitaram colaborar com a pesquisa. Os critérios de inclusão foram ministrar aula no curso da saúde no mínimo três anos na referida instituição e com carga horária superior a 12 horas semanais. Foram excluídos os docentes que estiveram ausentes no período da coleta, atuavam exclusivamente nos estágios supervisionados e não tinham disponibilidade para cooperar com o estudo.

A coleta de dados ocorreu de novembro de 2014 a fevereiro de 2015, cujas informações foram obtidas em oficina de capacitação e por meio da observação não participativa e sistemática

A oficina de capacitação foi estruturada e facilitada pela própria pesquisadora que tinha o intuito de fornecer informações sobre as técnicas das MA de ensino-aprendizagem para, posteriormente, serem implementadas em sala de aula. As oficinas aconteceram durante cinco

RIAEE - Revista Ibero-Americana de Estudos em Educação, Araraquara, v. 14, n. 2, p. 354-370, abr./jun., 2019. E-ISSN: 1982-5587. 
encontros consecutivos, no horário de 18 às 22 horas, em uma sala da própria IES, em que os 13 participantes conheceram e vivenciaram as MA e as estratégias educacionais.

Destaca-se que os cursos de capacitação docente ofertados pela IES acontecem uma a duas semanas antes do retorno dos alunos, no período das férias escolares. Nesta semana, os professores não estavam de férias e encontravam-se disponíveis para atividades propostas pela instituição na qual estavam vinculados. Dentre essas atividades, apontam-se as reuniões de colegiado e a geral, a preparação e os ajustes dos planos de ensino semestral, a semana pedagógica, com oferta dos cursos de capacitação docente. Em vista disso, as reuniões foram realizadas nesse período.

No primeiro encontro, foi explanado sobre os objetivos da oficina e entregue o material didático elaborado pela pesquisadora, denominado Caderno do Aluno, contendo as informações sobre o conteúdo programático a serem abordados, as competências e os objetivos a serem atingidos, a programação e o roteiro das atividades, os instrumentos de avaliação da oficina e de autoavaliação dos docentes, assim, facilitando o acompanhamento das atividades ofertadas em cada reunião. Também foi constituído o contrato de convivência, pontuando horários de início, intervalo e finalização das oficinas, bem como o uso restrito do celular. Nesse momento, os docentes receberam crachás que continham as iniciais do principal nome e do último sobrenome, essa forma de identificação foi posta para não prejudicar os dados coletados durante a observação. A seguir, foi realizada roda de conversa, com miniexposição dialogada sobre educação continuada, aprendizagem, significante, significado, signo, heutagogia, pedagogia e andragogia.

No segundo momento, foi utilizada a estratégia cinema com pipoca, em que todos assistiram ao filme "Minhas Tardes com Margueritte" e depois se formou uma roda de conversa para relacionar as cenas do filme com os temas aprendizado contextualizado, conhecimento prévio, aprendizagem significativa.

$\mathrm{Na}$ terceira noite, foram empregadas duas miniexposições dialogadas sobre metodologias tradicionais, metodologias ativas, Aprendizagem Baseada em Problemas (ABP) e problematização, além da vivência do grupo tutorial, etapa de encontro de análise do problema: desafios do processo ensino-aprendizagem na atualidade.

$\mathrm{Na}$ quarta reunião, foi trabalhado o fechamento do grupo tutorial, etapa encontro de resolução do problema, além da estratégia júri simulado para trabalhar as características, aplicabilidades, semelhanças e diferenças da problematização e da ABP 
E, no quinto e última oficina, foram usadas as táticas de miniexposição dialogada e as atividades em pequenos grupos, circuito e a redação a várias mãos, para versar sobre as estratégias educacionais. Ainda nesse momento, para verificar o alcance dos objetivos propostos, foram realizadas a avaliação de desempenho da oficina e autoavaliação dos participantes, por meio de questionário avaliativo anexado no caderno do aluno e, logo após preenchimento deste, foi entregue à pesquisadora.

Ao final de cada encontro, ocorreu o fechamento das atividades executadas, por meio do feedback oferecido pela pesquisadora/facilitadora da oficina.

Durante a realização da oficina, os 13 docentes foram observados de forma não participativa e sistemática, com intuito de identificar e descrever as ações dos participantes diante da execução das estratégias metodológicas recomendadas. Para anotação dos comportamentos observados nesta etapa, foi usado check list e diário de campo que foram preenchidos por um docente treinado e designado pela pesquisadora. As anotações efetivadas no diário de campo serviram para tornar a pesquisa de campo mais fidedigna.

O perfil dos docentes foi anotado em uma ficha cadastral que continha dados sobre idade, estado civil, salário, formação, titulação, anos de docência, horas de dedicação em sala da aula, vínculos empregatícios, além de conhecer a opinião sobre a viabilidade da implantação das MA de ensino.

Os dados coletados na ficha cadastral, nos questionários de avaliação e da observação foram analisados de acordo com as características quantitativas. Para análise dos dados quantitativos extraídos, estes foram expostos em números e percentuais apresentados em forma de tabelas para melhor articular os comentários e as discussões sobre os mesmos.

O projeto de pesquisa foi submetido ao Comitê de Ética e Pesquisa da Universidade Estadual do Ceará, tendo sido aprovado conforme parecer consubstanciado $\mathrm{n}^{\circ} 880.240$, em 21 de novembro de 2014. Os docentes que concordaram em participar da pesquisa, assinaram o Termo de Consentimento Livre e Esclarecido. Foram informados sobre objetivo, benefícios e riscos, e, caso desistissem de cooperar com a pesquisa, poderiam retirar-se a qualquer momento. Ainda, os procedimentos éticos asseguraram o sigilo das informações e o anonimato dos participantes.

\section{Resultados}

Os docentes apresentavam a média de idade 40,8 anos, 53,8\% eram mulheres, $61,5 \%$ casados, com renda familiar calculada em média de R\$ 8.125,00. Dos participantes, 69,2\%

RIAEE - Revista Ibero-Americana de Estudos em Educação, Araraquara, v. 14, n. 2, p. 354-370, abr./jun., 2019. E-ISSN: 1982-5587. 
tinham mais de um vínculo empregatício e trabalhavam na instituição pesquisada, com média de 5,4 anos. Quanto à graduação, 76,9\% possuíam bacharelado; e referente à titulação, 15,4\% eram doutores, $38,5 \%$ mestres e 46,1\% especialistas. Em relação à atuação na área de formação, os participantes apresentavam, em média, 16,9 anos e, para exercício da docência, a média foi de 8,7 anos de experiência.

Os resultados obtidos por meio do questionário foram compilados em três aspectos avaliativos, sendo o primeiro relacionado ao desenvolvimento das competências sobre as metodologias ativas; o segundo referente às atividades complementares; o terceiro concernente ao método de ensino-aprendizagem quanto ao desempenho nos trabalhos em grupo e o papel do facilitador. As anotações provenientes das observações foram organizadas em categorias de acordo com os itens identificados durante o curso.

No que concerne ao desenvolvimento das competências, obteve o conceito excelente, sobressaindo igualmente para todas em $92,3 \%$ no conhecimento dos conceitos, contribuições e limitações das MA e compreensão das etapas da ABP, na habilidade de lidar com a dinâmica do trabalho em grupo e na atitude de lidar com situações de conflito durante as atividades educacionais, favorecendo a empatia grupal (Tabela 1).

Tabela 1. Desenvolvimento das competências sobre as metodologias ativas de ensinoaprendizagem

\begin{tabular}{|c|c|c|c|}
\hline \multirow[b]{2}{*}{ Desenvolvimento das competências } & \multicolumn{3}{|c|}{ Conceitos } \\
\hline & $\begin{array}{l}\text { Regular } \\
\text { n (\%) }\end{array}$ & $\begin{array}{l}\text { Bom } \\
\text { n (\%) }\end{array}$ & $\begin{array}{l}\text { Excelente } \\
\text { n (\%) }\end{array}$ \\
\hline \multicolumn{4}{|l|}{ Aquisição de conhecimento } \\
\hline $\begin{array}{l}\text { Compreender os conceitos, contribuições e } \\
\text { limitações das } \mathrm{MA}^{*}\end{array}$ & - & $1(7,7)$ & $12(92,3)$ \\
\hline $\begin{array}{l}\text { Descrever estratégias educacionais utilizadas } \\
\text { nas MA }\end{array}$ & - & $2(15,4)$ & $11(84,6)$ \\
\hline $\begin{array}{l}\text { Conhecer o Arco de Maguerez e saber identificar } \\
\text { e utilizar as suas etapas como problematização }\end{array}$ & $1(7,7)$ & $4(30,8)$ & $8(61,5)$ \\
\hline $\begin{array}{l}\text { Compreender e identificar o grupo tutorial como } \\
\text { estratégia da } \mathrm{ABP} * *\end{array}$ & $1(7,7)$ & $1(7,7)$ & $11(84,6)$ \\
\hline \multicolumn{4}{|l|}{ Aquisição de habilidades } \\
\hline Lidar com a dinâmica do trabalho em grupo & - & $1(7,7)$ & $12(92,3)$ \\
\hline Resolver os problemas com soluções pertinentes & $1(7,7)$ & $3(23,1)$ & $9(69,2)$ \\
\hline \multicolumn{4}{|l|}{ Aquisição de atitudes } \\
\hline $\begin{array}{l}\text { Operacionalizar situações de conflito durante as } \\
\text { atividades educacionais, favorecendo a empatia } \\
\text { grupal }\end{array}$ & - & $1(7,7)$ & $12(92,3)$ \\
\hline Receber e fazer críticas & - & $2(15,4)$ & $11(84,6)$ \\
\hline Saber ouvir e falar nos momentos necessários & - & $3(23,1)$ & $10(76,9)$ \\
\hline
\end{tabular}

Fonte: Autores

RIAEE - Revista Ibero-Americana de Estudos em Educação, Araraquara, v. 14, n. 2, p. 354-370, abr./jun., 2019. E-ISSN: 1982-5587. 
Quanto às estratégias usadas durante as oficinas, foram avaliados os quesitos sobre conteúdo, exposição de forma clara, tendo as respostas compiladas em regular, bom e excelente. Demonstrou-se que o conceito excelente sobressaiu, sendo o júri simulado foi ressaltado em $84,9 \%$; seguidas do circuito, com 76,9\%; e igualmente com $69,2 \%$ para roda de conversa; e redação a várias mãos. No entanto, o cinema com pipoca e grupo tutorial não tiveram aceitação expressiva, predominando o conceito bom em 61,5\% e 53,8\%, respectivamente (Tabela 2).

Tabela 2. Estratégias utilizadas para trabalhar a temática abordada durante as oficinas de capacitação dos docentes

\begin{tabular}{lccc}
\hline \multirow{2}{*}{ Atividades complementares } & \multicolumn{3}{c}{ Conceitos } \\
\cline { 2 - 4 } & $\begin{array}{c}\text { Regular } \\
\text { n (\%) }\end{array}$ & $\begin{array}{c}\text { Bom } \\
\text { n (\%) }\end{array}$ & $\begin{array}{c}\text { Excelente } \\
\text { n (\%) }\end{array}$ \\
\hline Estratégias & & $5(38,5)$ & $8(61,5)$ \\
$\quad$ Miniexposição dos temas trabalhados & - & $4(30,8)$ & $9(69,2)$ \\
Roda de conversa & - & $8(61,5)$ & $5(38,5)$ \\
Cinema com pipoca & - & $7(53,8)$ & $6(46,2)$ \\
Grupo tutorial & - & $2(15,4)$ & $11(84,6)$ \\
Júri simulado & - & $3(23,1)$ & $10(76,9)$ \\
Circuito & - & $4(30,8)$ & $9(69,2)$ \\
$\quad$ Redação a várias mãos & - & &
\end{tabular}

Fonte: Autores

O segundo aspecto avaliativo relativo ao desempenho nos trabalhos em grupo, em 100\% dos docentes concordaram que os encontros estimularam as atividades de aprendizagem, a atmosfera do grupo foi agradável e os encontros foram produtivos. Quanto ao papel do facilitador, $100 \%$ referiram que o facilitador demonstrou conhecimento acerca das estratégias metodológicas trabalhadas e estimulou o grupo a estudar (Tabela 3). 
Tabela 3. Desempenho nos trabalhos em grupo e do facilitador durante as oficinas de capacitação dos docentes

事

\begin{tabular}{|c|c|c|c|}
\hline \multirow[b]{2}{*}{ Métodos de ensino-aprendizagem } & \multicolumn{3}{|c|}{ Conceitos } \\
\hline & $\begin{array}{c}\text { Discordo } \\
\text { n }(\%)\end{array}$ & $\begin{array}{c}\text { Neutro } \\
\text { n }(\%)\end{array}$ & $\begin{array}{l}\text { Concordo } \\
\text { n }(\%)\end{array}$ \\
\hline \multicolumn{4}{|l|}{ Desempenho nos trabalhos em grupo } \\
\hline Os participantes contribuiram ativamente na discussão & - & $1(7,7)$ & $12(92,3)$ \\
\hline Os encontros estimularam as atividades de aprendizagem & - & - & $13(100,0)$ \\
\hline A atmosfera do grupo foi agradável & - & - & $13(100,0)$ \\
\hline Os encontros do grupo foram produtivos & - & - & $13(100,0)$ \\
\hline \multicolumn{4}{|l|}{ Desempenho do facilitador } \\
\hline $\begin{array}{l}\text { Demonstrou conhecimento acerca das estratégias } \\
\text { metodológicas trabalhadas }\end{array}$ & - & - & $13(100,0)$ \\
\hline Estimulou o grupo a estudar & - & - & $13(100,0)$ \\
\hline As intervenções estimularam a discussão em grupo & - & $1(7,7)$ & $12(92,3)$ \\
\hline Em intervalos, avaliou o funcionamento do grupo & - & $2(15,4)$ & $11(84,6)$ \\
\hline Forneceu respostas durante as discussões em grupo & $2(15,4)$ & $1(7,7)$ & $10(76,9)$ \\
\hline
\end{tabular}

Fonte: Autores

Durante a observação, foi constatado, no quesito de relacionamento, unanimidade da presença do convívio interpessoal com empatia, seguidas de respeito $(92,3 \%)$ e acolhimento $(84,6 \%)$. Revelou-se que 92,3\% dos docentes possuíam postura ativa durante as oficinas e $76,9 \%$ participaram integralmente das atividades expostas, porém 69,2\% conduziam corretamente as estratégias trabalhadas. Os docentes demonstraram interesse em utilizar as MA em sala de aula, destes, $23,1 \%$ não apresentaram domínio ao utilizar as metodologias. O contrato de convivência foi cumprido pela maioria, estando presente o uso do celular, por 15,4\% dos participantes (Tabela 4). 
Tabela 4. Informações obtidas mediante as observações realizadas nas oficinas de capacitação dos docentes

\begin{tabular}{|c|c|c|}
\hline \multirow[b]{2}{*}{ Elementos observados } & \multicolumn{2}{|c|}{ Comportamento } \\
\hline & $\begin{array}{l}\text { Presente } \\
\text { n (\%) }\end{array}$ & $\begin{array}{c}\text { Ausente } \\
\text { n (\%) }\end{array}$ \\
\hline \multicolumn{3}{|l|}{ Relacionamento entre colegas e em equipe } \\
\hline Acolhimento aos colegas & $11(84,6)$ & $2(15,4)$ \\
\hline Convívio interpessoal com empatia & $13(100,0)$ & - \\
\hline Respeito aos integrantes & $12(92,3)$ & $1(7,7)$ \\
\hline \multicolumn{3}{|l|}{ Aplicabilidade das metodologias ativas } \\
\hline Demonstra interesse em utilizar em sala de aula & $13(100)$ & - \\
\hline Domínio no uso das metodologias ativas & $10(76,9)$ & $3(23,1)$ \\
\hline \multicolumn{3}{|l|}{$\begin{array}{l}\text { Participação e postura diante das atividades da } \\
\text { oficina }\end{array}$} \\
\hline Participação integral & $10(76,9)$ & $3(23,1)$ \\
\hline Postura ativa nas atividades & $12(92,3)$ & $1(7,7)$ \\
\hline Conduta adequada nas atividades & $9(69,2)$ & $4(30,8)$ \\
\hline Conversa paralela & $4(30,8)$ & $9(69,2)$ \\
\hline Uso de celular & $2(15,4)$ & $11(84,6)$ \\
\hline Saída de sala & $2(15,4)$ & $11(84,6)$ \\
\hline
\end{tabular}

Fonte: Autores

Quanto às sugestões para potencializar as oficinas de capacitação, 84,6\% dos participantes mencionaram que o programa foi abordado de forma significativa e eficaz, 30,8\% destacaram que seria necessária ampliar a carga horária para explanar as estratégias com maior profundidade, $76,9 \%$ solicitaram que as oficinas fossem semestrais para capacitar o corpo docente e, assim, uniformizar o uso das metodologias no cotidiano das aulas ministradas e $23,1 \%$ alegaram que os gestores precisavam aderir às MA, no que concerne a prover inserção das MA na instituição, educação permanente presencial e a distância, materiais e ambientes adequados ao uso dessas novas estratégias de ensino-aprendizagem.

Ademais, foi solicitado aos docentes que atribuíssem nota de zero a 10, simbolizando escala de aprendizagem extraída das atividades executadas nas oficinas. A média aritmética das notas atribuídas foi de 8,5. Ainda sobre a nota aferida a si, percebeu-se que a menor nota atribuída foi 7,0 , por apenas um participante $(7,7 \%)$, e a maior nota foi 10 , por dois participantes $(15,4 \%)$

\section{Discussão}

Vive-se, na contemporaneidade, importantes dilemas educacionais que, por mais evidentes que possam parecer, mantêm-se distanciando discursos e práticas educativas. Se de um lado ampliam-se as reflexões sobre as necessidades de transformação dos modelos de 
ensino-aprendizagem voltados ao desenvolvimento integral dos estudantes, por outro, ainda se conserva a tradição de ensino indiferente às novas descobertas sobre como as pessoas aprendem (MOURTHÉ JÚNIOR; LIMA; PADILHA, 2017).

Pesquisa nacional evidenciou que entre os 11 docentes entrevistados, predominaram mulheres (72,7\%), com idade entre 33 e 57 anos, com tempo de formação entre dez e 33 anos e de docência variando entre dez e 29 anos, sendo predominante a faixa intermediária de 11 a 14 anos. Os professores participantes possuíam cursos de pós-graduação, sendo três $(27,3 \%)$ com especialização, sete $(63,6 \%)$ com mestrado e um $(9,1 \%)$ com doutorado (FREITAS et al., 2016). Esses dados foram equivalentes aos encontrados neste estudo.

Dos participantes, predominaram o estado civil de casado e ter mais de um emprego, desta maneira, intensificando a renda familiar. Nesse ponto de vista, muitos docentes acumulam, em mais de um local de trabalho, carga horária superior a 40 horas semanais, a fim de adquirir remuneração digna que satisfaça as necessidades, ocasionando sobrecarga de trabalho que, juntamente com as obrigações familiares e sociais, resultam em problemas relacionados ao estresse professor (GOMES et al., 2016).

Na presente pesquisa, observou-se quantidade razoável de docentes com apenas pósgraduação lato sensu inseridos na docência superior e uma quantidade mínima de doutores nos cursos de graduação. Quantidade elevada de docentes com titulação especialista sugere carência de habilitação específica para exercer a carreira docente superior e o número pequeno de doutores infere desenvolvimento precário na área da pesquisa científica. Faz-se necessário que os profissionais estejam em constante capacitação para cada vez mais aprimorar competências no exercício do magistério.

As competências pedagógicas docentes centraram-se na necessidade de o professor buscar se aprimorar constantemente, de forma a adequar métodos às novas exigências curriculares preconizadas pelas Diretrizes Curriculares Nacionais (DCN) (BELFOR et al., 2018). A expressão competência está associada a três características conceituais: o primeiro de que ser competente é um estado inerente à pessoa, a pessoalidade; segundo, se é competente na ação de fazer algo com o fim de ou para; e em último, a competência se vincula ao sentido de bem, de algo que seja bem feito, bem executado e que bem resulte (MACEDO; CAETANO, 2017). Pode-se afirmar que competência se aproxima do conceito de ética enquanto reflexão e prática do bem pensar, fazer, agir e viver.

As necessidades atuais de capacitação profissional exigida pelo mercado de trabalho, o perfil dos discentes inseridos no ensino superior, o cumprimento das DCN e a fiscalização 
efetiva do Ministério da Educação faz com que as IES tenham preocupação constante em cumprir as medidas determinadas pelo avaliador da qualidade do ensino ofertado para não comprometer o reconhecimento dos cursos ou o credenciamento da instituição.

As alterações no panorama da formação profissional no ensino superior influenciam diretamente a formação do professor em seus diversos aspectos (MAKUCH; ZAGONEL, 2017). Nesse contexto, faz-se necessária a permanente preocupação com a formação docente, em que o educador deve, então, refletir sobre os três eixos cujo exercício do magistério está edificado: conhecimento científico (dimensão epistemológica), conhecimento didático (dimensão pedagógica) e conhecimento socializador contextualizado (dimensão políticosocial) e conscientizar-se de sua função como mediador/facilitador no processo ensinoaprendizagem.

O curso de capacitação apresentou aos docentes algumas estratégias de MA, possibilitando aos professores a constituição das competências no que concernem aos eixos do conhecimento, habilidades e atitudes. Revisão integrativa identificou que as possibilidades para desenvolver MA de ensino-aprendizagem são múltiplas, ainda listou os tipos e as estratégias de operacionalização das metodologias que estão sendo usadas no panorama da educação, como aprendizagem baseada em problemas; problematização do Arco de Charles Marguerez; pedagogia da problematização; estudos de caso; grupos reflexivos, interdisciplinares, de tutoria e facilitação; relato crítico sobre a própria experiência; socialização, mesas-redondas, plenárias, exposições dialogadas, debates temáticos, seminários, oficinas e leitura comentada; apresentação de filmes, interpretações musicais, dramatizações e dinâmicas lúdicopedagógicas; e portfólio e avaliação oral (autoavaliação, grupo, professores e ciclo) (PAIVA et al., 2016).

A interpretação das informações sugere que os treze participantes da capacitação docente adquiriram conhecimento suficiente sobre os conceitos e as estratégias de trabalho, utilizando as MA de ensino-aprendizagem. Contudo, a problematização através do Arco de Maguerez foi a estratégia com mais dificuldade referida, sugerindo tempo maior de trabalho para alcançar o grau de conhecimento necessário para introduzi-la no cotidiano docente.

A problematização e aprendizagem baseada em problemas são estratégias metodológicas ativas distintas, mas que apresentam semelhanças. Ambas propõem romper com os métodos tradicionais de ensino (BERBEL, 1998). Tanto a problematização como a aprendizagem baseada em problemas trabalham com problemas para desenvolver o processo ensino-aprendizagem, valorizando o aprender a aprender. A problematização utiliza-se do Arco 
de Maguerez para expor e transformar a realidade e a ABP utiliza-se do grupo tutorial para apoiar os estudos.

Durante o desenvolvimento da oficina de capacitação docente, pode-se analisar que os professores foram demonstrando maior afinidade por determinadas estratégias metodológicas. A participação durante as miniexposições apresentadas foi marcante, observando-se interesse crescente na miniexposição sobre significante, significado e signo, em que o ressignificar movimentou as opiniões em sala, despertando curiosidade por parte dos docentes participantes da oficina. Além disso, o momento ápice foi a roda de conversa com discussões e participação unânime da turma.

A apresentação do filme não foi unanimemente aceita pelos docentes, pois o clima de cinema na sala associado ao cansaço de um dia inteiro de trabalho pode ter contribuído com o índice de dispersão verificado para essa estratégia. O grupo tutorial foi referido como estratégia que necessita de mais tempo de execução para efetivação do aprendizado sobre a estratégia e houve desrespeito às falas de colegas, demonstrando a dificuldade de se trabalhar em grupo. A estratégia mais citada foi o júri simulado, que revelou potencialidades em argumentação e discussão de alguns participantes e o envolvimento de todos na atividade proposta. $\mathrm{O}$ dinamismo do circuito e sua proposta em buscar respostas a partir do conhecimento prévio fizeram dessa estratégia vivência positiva em grupo com alcance do objetivo. A caracterização e a imaginação favoreceram o sucesso do uso das estratégias das metodologias ativas.

As metodologias ativas visam promover: pró-atividade, por meio do comprometimento dos educandos no processo educacional; vinculação da aprendizagem aos aspectos significativos da realidade; desenvolvimento do raciocínio e de capacidades para intervenção na própria realidade; bem como a colaboração e cooperação entre participantes (LIMA, 2017). Para se trabalhar com MA de ensino-aprendizagem, é necessária mudança de comportamento, cujo docente despe-se do papel de professor, assuma o papel de facilitador e liberte-se da responsabilidade plena de educar os discentes, fazendo-os serem corresponsáveis nesse processo. $\mathrm{O}$ trabalho com as metodologias ativas requer saber trabalhar de forma respeitosa e harmoniosa com a equipe.

No entanto, existem desafios a serem superados para aplicação das MA de ensinoaprendizagem no cenário educacional. Em estudo de revisão integrativa, foram identificados quatro desafios principais: mudança do sistema tradicional de educação; dificuldade quanto à formação profissional do educador; dificuldade de contemplar os conhecimentos essenciais; e 
dificuldade para articular a parceria com outros profissionais no campo de atuação (PAIVA et al., 2016).

No que se referem ao desempenho nos trabalhos em grupo, o quesito da contribuição ativa dos participantes nas discussões foi avaliado com conceito neutro e os demais itens receberam somente conceito concordo. Também, a minoria permaneceu neutra em relação ao estímulo e à avalição por parte do facilitador, e alguns despontaram ausência de respostas para o grupo. Esses dados revelam que as atividades de grupo propostas pela capacitação docente foram satisfatórias, porém é fundamental que o facilitador reavalie esses dados contraditórios para melhor adequar as metas pedagógicas e, assim, absorver todo público-alvo de forma ativa, com conhecimento compartilhado integralmente.

Como o docente é visto como o mediador do processo de ensino e aprendizagem, este deve buscar meios que motivem mais os alunos a aprenderem por meio de novas metodologias e orientá-los para que as informações advindas desse momento tecnológico se tornem significativas; e, ainda, auxiliá-los na construção do conhecimento (SILVA; PRATES; RIBEIRO, 2017).

A maioria dos docentes observados manteve bom relacionamento no que se refere ao acolhimento, à empatia e às relações de respeito no trabalho em equipe. É sabido que a maior dificuldade enfrentada pelo trabalho em equipe deve-se, principalmente, ao não cumprimento das relações de respeito necessárias para se conviver em comunidade. Quando indagados quanto ao sentir-se estimulado a utilizar as estratégias de MA após conhecê-las e vivenciá-las na oficina ofertada, os docentes participantes sentiram-se estimulados, no entanto, a maioria demonstrou não apresentar domínio na aplicação das MA.

Verifica-se que os professores, quando exercem o papel de discentes, exibem comportamentos semelhantes a estes em sala de aula, comprometendo o desempenho, a postura autônoma diante das atividades e a corresponsabilidade no processo de ensino-aprendizagem. Outro fator observado foi a postura assumida diante do cumprimento dos pactos de convivência estabelecidos no início da oficina, em que a maioria dos docentes cumpriu com os pactos, assumindo postura correta e coerente.

Durante a capacitação, foi preciso o emprego das tecnologias para tornar mais compreensível e didático os tipos e as estratégias das metodologias ativas em sala de aula, como slides, computador, televisão, vídeos, dentre outros. Nesta perspectiva, é fundamental discutir a relação das tecnologias e o processo de ensino e aprendizagem. O professor se depara hoje 
com um universo tecnológico do qual precisa saber tornando-se um desafio para muitos professores (SILVA; PRATES; RIBEIRO, 2017).

O docente deve acreditar que o uso da tecnologia pode apoiar efetivamente o processo de ensino-aprendizagem e que, muito além de melhorar a organização e a visibilidade de alguns temas em suas aulas, pode, sim, contribuir para que questões importantes no processo de aprender, como a motivação do aluno para o aprendizado, o desenvolvimento de habilidades colaborativas, a interdisciplinaridade, as atividades de pesquisa, entre tantas outras (SCHUHMACHER; ALVES FILHO; SCHUHMACHER, 2017).

Por outro lado, o uso do celular em sala de aula foi visto como quebra de contrato de boa convivência, sendo apontado como obstáculo, caso fosse usado pelos docentes de forma indevida, sem fins didáticos. Os obstáculos didáticos são conhecimentos usados no processo de ensino-aprendizagem que produzem respostas simplificadas aos problemas e que, muitas vezes, produzem erros em diversos outros problemas, produzindo resistências à modificação ou mesmo à transformação. Na sala de aula, o obstáculo se apresenta quando o professor não consegue conduzir o processo, não contribuindo com a aprendizagem efetiva do aluno (CALDARELLI, 2017).

Nesse sentido, pesquisa em Minas Gerais mostrou que 64\% dos professores permitiam, às vezes, o uso do celular dentro da sala de aula e $91 \%$ dos professores consideravam que, às vezes, o celular possa ser um recurso pedagógico. Conclui-se, então, que o professor ainda não considera que o celular possa ser utilizado como recurso pedagógico dentro da sala de aula. Ademais, a discussão acerca do assunto divide muitas opiniões, algumas pesquisas mostram que os professores consideram que seja produtivo o uso deste recurso, outros não, acreditam que os alunos o utilizam para outras pesquisas que não sejam referentes à atividade da sala de aula. Apesar do resultado da pesquisa considerar que o celular não seja um recurso tecnológico auxiliar dentro da sala de aula, há justificativas que mostram o benefício deste recurso como ferramenta pedagógica (SILVA; PRATES; RIBEIRO, 2017).

Os docentes recomendaram que o curso de capacitação fosse instituído permanente no programa educacional da instituição, com carga horária mais extensa para abordar todas as estratégias das MA com maior intensidade. Ademais que o curso seja estendido para todo o corpo docente, com intuito de edificar as competências desses profissionais no uso das MA com exatidão e efetividade, desta forma, tornar uniforme e sistematizada a aplicação das MA no dia a dia em sala de aula. Em estudo realizado no Rio Grande do Norte, alguns docentes expressaram a ideia de que a formação continuada deveria ser ofertada, indicando que se faz

RIAEE - Revista Ibero-Americana de Estudos em Educação, Araraquara, v. 14, n. 2, p. 354-370, abr./jun., 2019. E-ISSN: 1982-5587. 
necessária realização de cursos de capacitação para todos os envolvidos no processo educativo, visando formar profissionais ativos e preparados para necessidades do mercado de trabalho contemporâneo (MESQUITA; MENESES; RAMOS, 2016).

Sobre a formação do professor, é inegável que sua função na sociedade se transformou, isto porque seu papel não se reduz à docência, envolve, atualmente, uma multiplicidade de saberes, fazeres, o que denota a emergência na arquitetura de competências complexas, ancoradas em componentes dos mais diversos, do aprender a aprender, da interação relacional, da dialogicidade, do trabalho cooperativo, dentre outras atuações. Formação que consiste em delinear conhecimentos, saberes, habilidades, atitudes, capacidades, valores e, naturalmente, competências, para melhor integração ao mundo do trabalho e que prepare o pedagogo para uma ação permanente na transformação de si e dos outros, entendendo o ato de educar sob o prisma de uma prática humanística (MACEDO; CAETANO, 2017).

Ainda, os professores abalizaram que os gestores devem ser conscientizados sobre a importância da utilização dos diversos tipos e estratégias de MA na atuação do magistério e que eles devem prover treinamentos permanentes, estruturas ambientais, materiais didáticos e tecnológicos necessários para implantação no cenário da educação.

Um dos grandes desafios para as IES no processo de inserção e utilização de MA de aprendizagem é estimular, capacitar o corpo docente, proporcionar infraestrutura para o emprego dos variados métodos de ensino-aprendizagem, definir diretrizes propiciadoras ao uso das metodologias ativas e a avaliação sistemática da eficácia de sua utilização. Além disso, para Caldarelli (2017), a IES deve manter treinamento e capacitação contínua para seu corpo docente. Por essa razão, Camas (2017) aponta que a educação inicial é tão importante quanto à continuada e preparar o docente é obrigação de uma IES, assim como oferecer-lhe condições de praticar, em sua ação pedagógica, novas formas de cuidar da aprendizagem.

O feedback de encerramento da oficina revelou expressões de interesse em conhecer melhor as MA de ensino e aprendizagem e as estratégias de MA, interesse no desenvolvimento de capacitações continuadas sobre a temática trabalhada, elogios proferidos como a melhor capacitação presenciada na instituição. Em estudo realizado na Universidade Federal do Amapá, foi evidenciada a importância de uma avaliação constante do corpo docente, a qual deve consentir feedback formativo aos educadores, indicando fragilidades e potencialidades, o que contribuiria para aplicar soluções às problemáticas referenciadas no processo de ensinoaprendizagem (BELFOR et al., 2018). 


\section{Considerações finais}

Como medidas institucionais para melhoramento da qualidade do processo de ensinoaprendizagem podem-se destacar: a atualização dos currículos de acordo com as necessidades atuais que exigem integralização maior entre as disciplinas; mudança comportamental do corpo docente e discente, atendendo às características desse público discente adulto, ou seja, participação ativa do aluno com corresponsabilidade no processo de aprendizagem; contextualização do ensino, viabilizando a aprendizagem. As medidas citadas são trabalhadas pelas MA de ensino-aprendizagem, além de serem aplicadas no ensino da saúde, por enfocarem a prática, a realidade.

Destaca-se como limitação do estudo a condução do curso pela complexidade das estratégias metodológicas trabalhadas e o curto espaço de tempo para desenvolvimento das práticas, porém as estratégias expostas favoreceram a troca de saberes e fazeres entre os participantes do grupo e facilitador. Recomenda-se mais treinamento e vivência com as estratégias das MA, para que inseguranças referentes à aplicação destas sejam superadas e que possam ser utilizadas nos programas educacionais como meio para transformar a realidade vigente das IES.

Para melhorar a preparação pedagógica dos docentes e o conhecimento sobre metodologias ativas, sugere-se o investimento em cursos de capacitação continuadas e treinamento de habilidades sobre estratégias de ensino que facilitarão a superação do comportamento tradicionalista presente entre os docentes das instituições de ensino.

\section{REFERÊNCIAS}

BELFOR, J. A. et al. Faculty teaching skills perceived by medical students of a university of the Brazilian Amazon region. Ciênc. Saúde Coletiva, v. 23, n. 1, p. 73-82, 2018.

BERBEL, N. A. N. A problematização e a aprendizagem baseada em problemas: diferentes termos ou diferentes caminhos? Interface Comun Saúde Educ., v. 2, n. 2, p. 139-154, 1998.

CALDARELLI, P. G. A importância da utilização de práticas de metodologias ativas de aprendizagem na formação superior de profissionais da saúde. Rev. Sustinere, v. 5, n. 1, p. 175-178, 2017.

CAMAS, N. P. V.; BRITO, G. S. Metodologias ativas: uma discussão acerca das possibilidades práticas na educação continuada de professores do ensino superior. Rev. Diálogo Educ., v. 17, n. 52, p. 311-336, 2016. 
FREITAS, D. A. et al. Saberes docentes sobre processo ensino-aprendizagem e sua importância para a formação profissional em saúde. Interface (Botucatu), v. 20, n. 57, p. 437-448, 2016.

GOMES, K. K. et al. Qualidade de vida e qualidade de vida no trabalho em docentes da saúde de uma instituição de ensino superior. Rev Bras Med Trab., v. 15, n. 1, p. 18-28, 2017.

LIMA, V. V. Constructivist spiral: an active learning methodology. Interface (Botucatu), v. 21, n .61, p. 421-434, 2017.

MACEDO, S. M. F.; CAETANO, A. P. V. A ética como competência profissional na formação: o pedagogo em foco. Educ Real, v. 42, n. 2, p. 627-648, 2017.

MAKUCH, D. M. V.; ZAGONEL, I. P. S. Pedagogical approach in the implementation of curriculum programs in nurse training. Esc Anna Nery, v. 21, n. 4, e201700252017.

MESQUITA, S. K. C.; MENESES, R. M. V.; RAMOS, D. K. R. Metodologias ativas de ensino/aprendizagem: dificuldades de docentes de um curso de enfermagem. Trab Educ Saúde, v. 14, n. 2, p. 473-486, 2016.

MOURTHÉ JÚNIOR, C. A.; LIMA, V. V.; PADILHA, R. Q. Integrating emotions and rationalities for the development of competence in active learning methodologies. Interface (Botucatu), v. 22, n. 65, p. 577-588, 2018.

PAIVA, M. R. F. et al. Metodologias ativas de ensino-aprendizagem: revisão integrativa. Rev Sanare, v. 15, n. 2, p. 145-153, 2016.

SCHUHMACHER, V. R. N.; ALVES FILHO, J. P.; SCHUHMACHER, E. As barreiras da prática docente no uso das tecnologias de informação e comunicação. Ciênc Educ., v. 23, n. 3, p. 563-576, 2017.

SILVA, I. C. S.; PRATES, T. S.; RIBEIRO, L. F. S. As novas tecnologias e aprendizagem: desafios enfrentados pelo professor na sala de aula. Debate, v. 15, p. 107-123, 2017.

\section{Como referenciar este artigo}

VELOSO, Mariana Dond.; PEQUENO, Alice Maria Correia.; NEGREIROS, Francisca Diana da Silva. Metodologias de aprendizagem no ensino superior de saúde: o fazer pedagógico. Revista Ibero-Americana de Estudos em Educação, Araraquara, v. 14, n. 2, p. 354-370, abr./jun., 2019. E-ISSN: 1982-5587. E-ISSN: 1982-5587. DOI: 10.21723/riaee.v14i2.11860

Submetido em: 28/10/2018

Revisões requeridas: 05/11/2018

Aprovado em: 15/12/2018 